\title{
The Historical Perspectives of Stereotypes on African-American Males
}

\author{
Evi Taylor ${ }^{1}$ (D) $\cdot$ Patricia Guy-Walls $^{1} \cdot$ Patricia Wilkerson $^{1} \cdot$ Rejoice Addae $^{1}$
}

Published online: 7 May 2019

(C) Springer Nature Switzerland AG 2019

\begin{abstract}
Stereotypes are ingrained in the fabric of the USA and coincide with the institution of slavery. The expected behaviors of AfricanAmericans are fueled by stereotypes maintained by the status quo. Throughout US history, the stereotyping of African-Americans, particularly males, has had a negative impact on African-American families and communities. For instance, the belief that AfricanAmericans are unintelligent, lazy, violent, and criminals has affected educational outcomes, employment opportunities, socioeconomic status, and the dismantling of African-American families and communities. Educators, businessmen, and law enforcement often believe these stereotypes, which influences their treatment of African-Americans. The oppression of African-Americans is a critical human rights issue that has to be addressed in social work practice. This article highlights a historical overview of how stereotypes have contributed to a denial of human rights, evidenced by inequalities in education, employment, and the justice system. Recommendations for culturally competent interventions and practice to improve social equity are discussed.
\end{abstract}

Keywords African-Americans $\cdot$ Stereotypes $\cdot$ Inequalities $\cdot$ Cultural competence

Stereotypes have a long and convoluted history in the USA, widely influencing African-American males who are the most visibly stereotyped racial group in the USA (Harpalnai 2017). This article will conceptualize stereotypes as generalizations about social groups that are rigidly held despite not being proven to be true. Regardless of the accuracy of the stereotype, it is incorporated into the individual's belief system (Judd and Park 1993). These fixed impressions of the shared attributes of a group of people are broadly held by society and "often aid people in making sense of social settings, situations, and interactions with others" (Nasir 2012; Strangor 1994 as cited by Larnell et al. 2014, p. 49). According to Larnell et al. (2014), stereotypes are linked to biases, prejudice, and systemic discrimination. They are a major factor influencing educational outcomes, employment opportunities, disproportional incarceration rates, and brutal treatment (Hadden 2001), resulting in the breakdown of AfricanAmerican families. Many African-Americans, particularly males, have been stereotyped as dumb, violent, dangerous criminals (Oliver 2003). The problem with stereotypes is that they limit

Evi Taylor

etaylor@astate.edu

1 Arkansas State University, P.O. Box 2460 State University, Jonesboro, AR 72467, USA opportunities for specific groups. The stereotypes perpetuated against African-American males often result in oppression, which is correlated with poverty and a host of other negative outcomes. This is a critical human rights issue that needs to be addressed in social work practice.

Striving to eliminate oppression, discrimination, poverty, social injustices, and violations of human rights continues to be an important goal for social workers. According to the U.S. National Association of Social Work Code of Ethics (NASW Code of Ethics, 2017, Preamble), "The primary mission of the social work profession is to enhance human well-being and help meet the basic human needs of all people, with particular attention to the needs and empowerment of people who are vulnerable, oppressed, and living in poverty." Social justice is a core value of the social work profession which is congruent with the rights framed by the Universal Declaration of Human Rights (UDHR) (Rozas and Garran 2016). Therefore, it is important that social workers practice from a human rights perspective to seek to understand the nature of oppression experienced by African-American males, address these problems by advocating on behalf of this marginalized group, and provide culturally competent services to ensure that AfricanAmerican males receive basic human rights identified in the UDHR. Social workers have a responsibility to understand the client, despite differences in beliefs, values, or choices, and to 
empower them to make the best decisions for themselves (Wahler 2012). The purpose of this paper is to increase awareness of the impact of stereotypes on African-American males by highlighting a historical overview of how stereotypes have contributed to a denial of basic human rights evidenced by inequalities in education, employment, and the justice system. Recommendations for culturally competent interventions and practice to ensure human rights will be discussed.

\section{Overview of Slavery}

Stereotypes about African-Americans in the USA are products of the institution of slavery. These deeply held beliefs stem from White racist attitudes that were operationalized through oppressive and discriminating actions that idealized how slaves should think and behave. Many White slave owners developed beliefs (stereotypes) to rationalize their economic, social, and political dominations (Feagin and Feagin 1999). Owning slaves symbolized upper class status among White supremacists who felt compelled to use violence to quell slave resistance through brutalizing treatment. This action dehumanized slaves, relegated their roles, and limited their activities to those deemed only important to their owners. The constraints of social control determined individual and familial relationships and behavioral activity that slaves portrayed. For example, slaves were stripped of their own cultural beliefs to conform to slave owners' expectations. The brutal and dehumanizing treatments were upheld through legal support on state and government levels, politicized as necessary to keep White people in control and became commonplace (Hadden 2001).

For slave owners, their strong stereotypical beliefs governed how African-Americans were to be treated, never as individuals, but always collectively. Hence, the racist premises from which laws and policies were based maintained societal perceptions of African-Americans. Even after slavery was abolished, the standards for treatment of African-Americans remained the same. When the slave population outnumbered the White population, political forces were established to regulate the AfricanAmericans to "keep Whites safe" from slaves resisting to the idealized expectations of Whites. The political forces were patrols organized to enforce the superiority-inferiority complex held today toward African-Americans (BLEAUSA 2014).

Slaves were property and were overseen by slave patrols to ensure stability for socioeconomic purposes for slave owners. Slave patrol, the first formal arrangement of the police, duties entailed maintaining White supremacy over AfricanAmericans (Turner et al. 2006). When slaves ran away, the patrol had the authority to hunt down and return them to their owners. To deter others from running, they would beat, maim, lynch, or just kill the slaves (Chaney and Robertson 2015). This horrific treatment was condoned and politicized particularly by southern states for the sole purpose of keeping
African-Americans under control. The dominant group's ethnocentrism preserved its status within the context of White supremacy, and African-Americans were subjected to a creation of a collective identity manufactured by former slave owners. These stereotypical beliefs hold firmly to the perception that African-American males, among other things, behave like savage beasts, are stronger than White men, lust for the blood of White women, and can tolerate more pain than White people (Plous and Williams 1995).

These stereotypes and the treatment of African-Americans males have been seen throughout history. Systemic racism in schools, the workforce, and the justice system perpetuates the negative stereotypes of African-American males, which results in fewer opportunities, lower educational and employment outcomes, and higher incarceration rates, which often lead to self-fulfilling prophecy. Although slavery "ended" with the Emancipation Proclamation of 1863, negative stereotypes and unjust treatment prevailed. For example, the Jim Crow Laws from 1876 to 1965 ensured that AfricanAmericans were not given the same rights of citizenship as White Americans. During this time, legal racial separation was promoted (Plessy vs. Ferguson) and "White Privilege" that was developed during slavery continued. Caucasians were entitled to the best educations, had the higher paying jobs, and lived in model neighborhoods, which is very similar in today's society. Although the United Nations adopted the International Convention on the Elimination of All Forms of Racial Discrimination (CERD) in 1965, the USA has not adhered to these international standards (Henderson 2013). The USA is often considered a leader in the human rights movement by advocating for human rights around the world; however, African-Americans have yet to realize equal opportunities promised in the CERD. As a result, the USA lags behind the rest of the world when it comes to racial equality (Henderson 2013).

\section{Stereotypes and Education}

Many African-Americans were hopeful of equal educational opportunities with Brown vs. Board of Education (1954), a landmark case outlawing state laws establishing separate schools for Black and White students (Caldwell and Obasi 2010). However, it is debatable whether the first Black students who attended integrated schools were receiving equal educational opportunities. These students were escorted to school by the National Guard, they had to be protected from the White adults who were protesting, and they were not able to participate in activities with the White students. For example, Ruby Bridges (2001) the first African-American to attend a White school in Louisiana, entered school each day with people yelling at her, making threats, holding up signs stating "We want to keep our school White," and "Integration 
is a moral sin." Because of the fear of Blacks due to stereotypes ingrained in society, White adults protested and traumatized a young Black child. As a result, Ruby reported having nightmares every night about the black baby doll in a coffin that one of the protestors held in front of Ruby as she entered the school.

Although Ruby was allowed to be in the same building as the White children, her experience was very different from her White counterparts. She had a teacher in a classroom by herself but was not allowed to interact with any of the other children (Bridges 2001). She was isolated and verbally attacked by the community on a daily basis. Ruby's traumatic experience, like the experiences of many African-American males today facing systemic racism (often originating with stereotypes), is a violation of the UDHR. Article 5 in the UDHR states "No one shall be subject to torture or to cruel, inhumane or degrading treatment." Article 26 states, "Education shall be directed to the full development of the human personality and to the strengthening of respect for human rights and fundamental freedoms. It shall promote understanding, tolerance, and friendship among all nations, racial, or religious groups, and shall further the activities of the United Nations for the maintenance of peace" (UDHR 1948). With systemic racism throughout the US educational system, these Articles in the UDHR remain unenforced.

Despite efforts to desegregate schools and provide all children with equal educational opportunities, over 50 years after the decision of Board versus Brown, there continues to be disparities in resources received by schools in White communities compared to those in Black communities. The unevenly distributed resources among schools perpetuate the race achievement gap, which continues to be a big concern because Black students continue to lag behind their White counterparts in terms of academic outcomes. For instance, only $17 \%$ of African-Americans, compared to $46 \%$ of White students, are reading at or above proficient levels in 12th grade (The nations report card 2013); the 2015 ACT scores for AfricanAmericans were 17.1 compared to 22.4 for their White peers; the 2013-2014 high school graduation rates for AfricanAmericans were $73 \%$ compared to $87 \%$ of their White counterparts; and in 2012-2013, 69\% of bachelor degrees were held by Caucasians and only $11 \%$ by African-Americans (National Center for Education Statistics 2016). AfricanAmerican males suffer from higher high school dropout rates and lower college entry completion rates than any other group (Johnson-Bailey et al. 2014). According to the 10th Biannual Schott Foundation for Public Education (2013), during the 2012-2013 school year, 40\% of African-American males dropped out of high school and only $60 \%$ earned their high school diplomas compared to $80 \%$ of their White male counterparts. Caucasians also outperform African-American students at the collegiate level. While only $42 \%$ of AfricanAmericans graduate from college, $62 \%$ of their White peers graduate. African-American females also graduate at higher rates (46\%) than African-American males (35\%).

Herrnstein and Murray (1994) theorized that intelligence is inheritable and that both genes and genetics contribute to racial differences in intelligence. The belief that Black people are intellectually inferior to White people has influenced the stereotyping of Black students (Diamond 2006; James 2012). Believing stereotypes contributes to teachers having low expectations for African-American students (Mathew 2011; Tenenbaum and Ruck 2007); having perceptions that African-Americans, particularly males, are more hyper, immature, impulsive, and aggressive (Ford and Whiting 2007); and making inappropriate referrals to special education due to mistaking cultural differences for cognitive and behavioral disabilities (Neal et al. 2003). Teachers report that Black boys have more behavioral problems and have fewer interpersonal skills than White boys and Black girls (Mathew et al. 2010), causing Black male students to be overrepresented in lower track and special education classes (Diamond 2006), underrepresented in advanced classes (Henfield et al. 2008), and more likely to receive detentions and suspensions (Mattison and Aber 2007). Teachers making referrals based off the stereotypes of African-American intelligence are perpetuating the race achievement gap and may explain why AfricanAmericans are half as likely to be placed in honors classes or advanced placement and 2.4 times more likely to be placed in remedial classes (Frye and Vogt 2010). When teachers have low expectations for their students, the students tend to have lower academic motivation and academic outcomes (Cokley et al. 2004).

According to the National Center for Education Statistic (NCES) (2010), there is a significant discipline gap; one out of every two African-Americans is suspended sometime during their education compared to one out of every five Caucasian males or one out of ten Caucasian females. These consistent patterns of disproportionate discipline sanctions issued to Black students have been well-documented (Diamond 2006; Gregory et al. 2010). The school suspension rate in the USA is three times greater for African-Americans than for White students (US Department of Education 2010). Twenty percent of African-American male students are given out-ofschool suspensions compared to $6 \%$ of White males (US Department of Education Office for Civil Rights 2014). Disparities in discipline are seen as early as pre-school. For instance, African-American pre-school students are more than three times as likely to be sent home for misbehaving as White children. These disparities continue in $\mathrm{K}-12$ th grade. In 20132014, $18 \%$ of African-American boys were suspended compared to $10 \%$ of African-American girls, $5 \%$ of Caucasian boys, and $2 \%$ of Caucasian girls (Sparks 2016). According to the San Francisco Chronicle, almost 20\% of Oakland's Black male students were suspended at least once in 2011, six times the rate of White students (Lyfe 2012; as cited by 
Rudd 2014). In Chicago public schools, Black students comprised $45 \%$ of the student body during the 2009-2010 academic year but $76 \%$ of the suspensions (New York Times Education 2012, as cited by Rudd 2014). These alarming disparities are seen in states across the nation.

The research consistently shows that the behaviors of African-American male students are more harshly perceived than behavior of other ethnic groups evidenced by the disproportionality in suspension rates and other types of school discipline (Givens et al. 2016). This is likely due to the stereotypes that African-American males are aggressive. According to Skibam et al. (2014), the overrepresentation of suspensions for African-American boys are for those infractions that are subjectively determined such as disobedience or disrespect toward educators. While $42 \%$ of students are diverse, $90-92 \%$ of teachers are White (Ford and Whiting 2007). The existing research suggests that teachers' stereotypes influence their implicit bias, which mirror those biases of the general population. For instance, 136 teachers from 6 schools were asked to watch a video of students walking. The results showed that the teachers perceived the AfricanAmerican male students walking with a stroll (a popular cultural style of walking displayed by many African-American males) to be more aggressive, lower in achievement, and more likely to need special education (Neal et al. 2003). Therefore, it can be concluded that teachers' stereotypes are influencing their actions toward African-American male students, resulting in lower expectations and disproportional suspension rates and special education referrals. These negative school experiences associated with racism (fueled by stereotypes) affect African-American male students' academic motivation and school achievement (Ogbu 2004), further perpetuating the achievement gap.

Stereotypes leading to experiences with racism and discrimination in school can be very stressful for students of all ages. Experiences with racism can also be traumatic. However, when discussing types of trauma, it is rare that racism is included. Trauma is an experience or repeated events that completely overwhelms an individual's ability to cope (Giller 1999). Traumatic experiences are unexpected, the person tends to be unprepared for it, there is nothing the person can do to stop it from happening, and it may be a single or reoccurring event (Robinson et al. 2018). These are all characteristics of racism. Yet, when discussing trauma, rape, abuse, and natural disasters are acknowledged, but not racism. Increased stress, impaired concentration, depression, low self-esteem, self-hatred, anger, irritability, and fear can all be psychological effects of perceived racism. Perhaps it is the stress/trauma of the perceived stereotypes and racism that is influencing academic outcomes of African-American males. Reynolds et al. (2010) found that race-related stress predicted both intrinsic and extrinsic motivation in African-American students. Discrimination has also been associated with lower grades, academic self-concepts, and school importance attitudes (Chavous et al. 2008).

\section{Stereotypes and Self-Concept}

Throughout history African-Americans have consistently been dehumanized, evidenced by the US constitution considering slaves three-fifths a person, the legalization of slave lynchings, the adoption of Jim Crow Laws, and most recently, police brutality against unarmed African-American males. When individuals are continually degraded and dehumanized, they often believe the stereotypes about their group and internalize the oppression they experience. Internalized oppression refers to the subordinate group adopting the dominant group ideology, resulting in the acceptance that their subordinate status is deserved, natural, and inevitable (Pike 2010 as cited by Aguilar 2015). Many African-Americans suffer from identity threat, as they believe the stereotypes and identity contingencies assigned to them by the dominant culture. This is seen in early elementary age children. Clark and Clark conducted a doll study in 1939 which children where shown a Black and a White doll and asked a series of questions about the doll. The results of the study showed that both Black and White children had more favorable responses toward the White doll and more negative reactions to the Black doll. The Black doll was considered to be the ugly doll, the bad doll, the dumb doll, and the mean doll. These doll studies have been reenacted several times over 60 years with similar results (CNN 2010). Starting at an early age, many Black children are exposed to negative stereotypes about their culture, often resulting in negative racial identities. The media often stereotypes AfricanAmericans, particularly males, as criminals, drug addicts, unintelligent, and jobless (Oliver 2003). When students believe these stereotypes about themselves, it affects their school performance (self-fulfilling prophecy) which will impact the types of jobs they attain in the future, their socioeconomic status, the communities they live in, and their family life.

These negative stereotypes of African-American males also influence the structural pattern of school districts throughout the USA (Diamond 2006), teachers perceptions (Neal et al. 2003), students' motivation (Ogbu 2004), performance on tests (Steele and Anderson 1995), graduation rates (Fisher 2009), and students' beliefs about their academic abilities (Steele and Anderson 1995). According to Ogbu (2004), people who are discriminated against and devalued in a society begin to believe and accept the negative stereotypes about themselves. Thus, they act according to the perceptions and it becomes reality (self-fulfilling prophecy). Ogbu (2004) refers to African-Americans as "caste-like" minorities because they were involuntarily incorporated into American society, have often been victimized by job ceilings keeping them in low-paying jobs that require little education, and view their 
unequal status in society as irreversible. Thus, AfricanAmericans do not see the value of an education because of the limited opportunities available to them. Environmental factors, lack of resources, stereotypes, and institutional racism are rarely considered by the mainstream population when considering the race achievement gap. Instead, throughout history, these disparities in educational outcomes have been utilized to support stereotypical views of African-American male intelligence.

\section{Stereotypes and the Work Force}

The poor educational outcomes of African-American males drastically impact African-American families and communities because most high-paying jobs require a diploma or some type of specialized training. If $40 \%$ of African-American males are dropping out of school, it will be very likely that they will live in poverty and have a difficult time providing for their families. In 2010, the unemployment rate for AfricanAmerican males over age 20 was $17.5 \%$ as compared to $7.9 \%$ for Caucasians (US Department of Labor, Bureau of Labor Statistics 2011) and 27.4\% of African-Americans were poor compared to $9.9 \%$ of Caucasians (U.S. Bureau of the Census 2010).

One factor affecting African-American employment is stereotypes held by employers that often result in covert racism in the hiring process (Cornelius 2013). Bertand and Mullainathan (2004) found that in identical resumes, altering the name from an European name to an African-American sounding name resulted in the European name receiving $50 \%$ more call-backs from employers (Blackmon and Thomas 2014). Therefore, obtaining employment for African-Americans is affected by stereotypes. According to the Harvard Law Review (1991), African-American men have many characteristics (verbal directness, expressive, assertive, etc.) that conflict with a predominantly White work environment. These perceived characteristics are stereotypes held by society that explain discrimination, such as the disproportionate salaries and employment rates among African-American men (Cornelius 2013). According to Cornelius (2013), African-American professional men are twice as likely to be unemployed and earn 20\% less than their White counterparts (Current Population Survey 2008). Of African-American employed men, only $22 \%$ are in management/professional jobs compared to $33 \%$ of White men (US Department of Labor, Bureau of Labor Statistics 2007).

Pager (2003) conducted a study of Black and White men who applied for hundreds of low wage jobs. Their resumes were equivalent differing only in race. The results of the study showed that African-American male applicants are less likely to be invited to interview, thereby providing fewer opportunities to establish rapport with the employer and demonstrate their skills. African-American males are also less than half as likely to receive consideration by employers as their White counterparts. Pager also found that criminal convictions were less problematic for the White participants. The White males who reported that they were just out of prison were as likely to be called back for a second interview as African-American men who had no criminal history at all. Among AfricanAmerican males without criminal records, only $14 \%$ received call-backs compared to $34 \%$ of their White non-criminal counterparts. White men with criminal records received more favorable treatment (17\%) compared to African-American males without (14\%). Criminal records for AfricanAmerican men are interrelated to the criminal justice system and difficult to overcome due to the convictions reinforcing longstanding stereotypes of African-American men.

Stereotypes also play a major role in work evaluations and promotions. Rosette et al. (2008) found that individuals develop a set of beliefs about the behaviors and characteristics of a business leader. Being White is considered a characteristic of the prototypical business leader, and this commonly held belief may lead to biased evaluations of minority leaders, particularly African-Americans who are stereotyped as being lazy and incompetent (Rosette et al. 2008). These stereotypical characteristics of a leader explain why research shows that White leaders are perceived as more effective and successful than Black leaders (Rosette et al. 2008). Racial stereotypes also explain why employees view African-Americans as lacking the knowledge and skills necessary for high-level positions (Cunningham and Bopp 2010 cited by Steward and Cunningham 2015).

\section{Stereotypes and the Justice System}

Many incarcerated African-American males have limited education. Stereotypes influence their school attendance, referrals for suspensions and expulsions, and completion rates (Diamond 2006). The correlation between high school dropouts and prison records has been a concern across the nation. The Justice Policy Institute found that $52 \%$ of AfricanAmerican males who did not graduate high school had a prison record by the time they were 30 (Bethell 2012).

Stereotyping African-Americans is prevalent in the criminal justice system. Tragic police shootings of innocent African-American males are happening at alarming rates. Too often, African-American males are stereotyped as violent, dangerous, and criminals, which reflects a long history of slavery and stereotypes (Oliver 2003). Previous research has shown that White people express greater fear of crime when in the presence of African-American men and give more harsh recommendations for African-American suspects than for White suspects (Mauer 2011). African-Americans are incarcerated five times more than Caucasians and are 2.5 times 
more likely to be searched when stopped by the police. Although African-Americans make up only $12 \%$ of the US population, African-American men account for $34 \%$ of drug arrests, and $40 \%$ of the total prison population (Darensbourg et al. 2010). It is estimated that one in every three AfricanAmerican men born today will be imprisoned sometime during their lifetime (Mauer 2011). There is also strong evidence that shows that race plays a role in determining death sentences; individuals who kill White people are four times as likely to receive death sentences as those who kill AfricanAmericans (Mauer 2011).

The mass incarceration of African-American males is reducing family household incomes and producing significant strains on the African-American community. AfricanAmerican children are nine times more likely to have an incarcerated parent, which is the largest factor contributing to father-child separation in African-American families (Perry and Bright 2012). Single parent families are more likely to be in poverty, and there is a correlation between poverty and education outcomes, employment, and the likelihood of engaging in criminal activity (Comfort 2012; Darensbourg et al. 2010).

The media also plays a role in perpetuating stereotypes of African-American males as violent criminals. Realitybased TV shows demonstrate that White police officers are more likely to employ force against Black and Latino suspects than toward White suspects (Oliver 2003). Although there is often bias in the way in which African-American males are depicted in the media, these reality TV recordings are congruent with what is happening in many communities across the USA. AfricanAmerican men are the target of mistakenly placed police aggression, which confirms that race plays a role in false assumptions of dangerous individuals (Oliver 2003). A study of deadly force by Philadelphia police supported the idea that police are susceptible to implicit bias (Fachner and Carter 2015). The study examined the label of threat perception failure. In these instances, the officers believed that the person was armed, and in many instances, it turned out not to be true. The findings revealed that failures were more likely to occur when the subject was Black or Latino (Fachner and Carter 2015). There have also been a plethora of shoot/ do-not-shoot studies in which a subject is sitting in front of a computer monitor and photos pop up very quickly on the screen showing a White or a Black man. The man either has a gun or a neutral object like a cell phone in his hand. The subject is told to hit the shoot key if they see a threat and if a threat is not seen to hit the "do not shoot" key. The findings revealed that people were quicker to shoot an unarmed African-American man than an unarmed White man, suggesting implicit bias affects these actions (Department of Justice Report 2016). Police officers, like many other people, have an implicit bias linking AfricanAmericans males to crime. Therefore, Black crime implicit bias is impacted in the use of deadly force against African-American males in the USA.

The undergirding perceptions for treatment of AfricanAmerican males were born out of the policing policies established from slavery and the Black Codes in the Deep South (BLEAUSA 2014, p2). This barbaric dehumanizing handling of African-Americans continued post-legal slavery and after the Civil War (Chaney and Robertson 2015). Just as alarming, the composition of the patrollers was typical semblance of early police forces in the USA (all White males), who were given legal authority to mistreat African-American males in any manner they saw fit. During the Civil Rights era, it became public knowledge that African-American males were victims of police brutality and yet the mysterious uninvestigated deaths "in the line of duty" were publicly acceptable. Today's trend of unarmed African American males being killed by police is news-worthy because of videos and public awareness of the real incident. Dulaney (1996) suggests that these shooting are the same type of violent policing that African Americans have been receiving since the 17th century.

These incidents of police brutality can be very traumatic in the African American community. Some African American males may be experiencing PTSD symptoms due to discrimination (Sibrava et al. 2019). However, they may not be validated by mental health professionals because racism has not traditionally been considered traumatic and there is limited research examining the relationship between discrimination and PTSD (Sibrava et al. 2019). It is important to consider that many African American males live in fear because it is not uncommon for them or someone they are acquainted with to be treated unfairly, discriminated against of even harassed by the police or someone in authority.. If African-American males do not have a personal experience with racism, they often witness it on television/social media. It is very difficult to excel in school, work, or other areas of one's life when safety needs are not met. Even if these incidents of perceived stereotypes and racism discussed throughout the paper at any level (school, work, in the community) were not experienced directly, African-American males can still experience secondary trauma by hearing the stories of other African-Americans who have experienced trauma as a result of racism.

Smith and Holmes (2003) found that brutality toward African-American males occurs because (1) authorities and White citizens tend to stereotype minorities as dangerous and criminally prone; (2) authorities see racially dissimilar minority groups as threatening to the existing social order; and (3) the police may perceive poor minority citizens as a direct threat to their well-being. Jennings (2011) suggest that the brutalizing of African-Americans is so routinely done by the police that too often the public thinks the behavior is 
normal. The main point is that the police "carry the memories and programmed racism forming their origination" (p.77). As previously noted, Whites devalued African Americans and used slave patrols to systematically control them and protect the interest of slave owners Today, the police fulfill the same roles and often feel justified in their efforts to carry out past practices of law enforcement functions. Hence, shooting and killing unarmed African-American males continue the normalizing of controlling African-Americans and protecting the White community (Turner et al. 2006). Police brutality often goes unreported or unpunished, which is a clear violation of the Convention on the Elimination of All Forms of Racial Discrimination (CERD) (Henderson 2013).

\section{Implications for Social Work Practice}

The stereotypes of African-American males are an ongoing concern in the USA dating back to slavery. These stereotypes are embedded in the US culture and often result in systematic racism. There is not one intervention that can miraculously stop the negative stereotypes of African-Americans or the racism in the schools, workforce, and judicial system. However, cultural competency training can be a first step in reducing the negative stereotypes, which may decrease some of the systematic racism discussed throughout this paper. Teachers, business people, police officers, and all professionals need cultural competency training from a human rights perspective to develop a sense of awareness and a skill set to work effectively with diverse populations.

\section{Cultural Competency Interventions}

The authors are aware that cultural competency trainings are not the total solution to dismantling stereotypes. However, the general notion that the unconscious significantly influences human behavior is a noted fact. Earlier documentation presented by Freud continues to the present day (Nosek et al. 2011). In order for society to move beyond the subconscious or unawareness of implicit bias, individuals must begin the process of recodification of stereotypes that are directly tied to the unconscious thoughts associated with racial groups, especially African-American males. Cultural competency training has been successful in some instances in dispelling stereotypes that decrease institutional racism. Although cultural competency training alone is not sufficient to address more than 200 years of bondage, oppression, discrimination, and injustices that have played a major role in traumatizing African-American males, it is the first step to begin the long overdue process of reducing stereotypes, while improving cultural sensitivity. The goal of cultural competency training is to (1) increase awareness, (2) gain knowledge, and (3) acquire skills to work with diverse cultures (Hickey 2016). The literature has documented that when people become aware of how stereotypes influence their behavior and gain knowledge about other cultures, they are able to understand, communicate, and effectively interact with people across cultures. It is imperative that the five core notions of human rightshuman dignity; non-discrimination; civil and political rights; economic, social, and cultural rights; and solidarity rightsare integrated in cultural competency training (Rozas and Garran 2016).

Awareness Increasing awareness about the negative impacts of stereotypes on African-American males is an essential first step to increasing social equity mandated by the UDHR (fair access to resources such as education, healthcare, jobs, etc.; full participation in the political and cultural life in one's community; and self-determination in meeting one's fundamental needs). Many professionals are reluctant to believe that their own behaviors, their peers' behavior, and their institution's policies may conflict with their professional ethics (Geiger 2006 cited by Griffith et al. 2007) and may be contributing to institutional racism. For this reason, it is important to practice from a social justice framework to raise consciousness about power and privilege and to encourage advocating against structural forces that violate human rights and perpetuate racism. Many African-American men are resistant to receive medical treatment and mental health services, to participate in school activities, or to interact with the police due to fear and lack of trust, resulting from institutional racism. Therefore, it is imperative that medical and mental health professionals, educators, business people, law enforcement, and politicians recognize the biases they possess that may be negatively influencing the services they provide.

One effective way to combat stereotypes is to increase awareness of how stereotypes affect decision-making (Devine et al. 2012). Becoming aware of one's beliefs is the first step to changing values, beliefs, and behaviors (Wahler 2012). There are many activities/exercises/surveys that can be used to increase awareness about one's stereotypes. Asking questions regarding racial attitudes; and characteristics, beliefs, and perceptions of various populations can help identify a person's tendency to respond with prejudice. People need to be aware of when biased responses are likely to occur and how to replace those biased responses with responses more consistent with their values (Devine et al. 2012). Simply being aware one has stereotypes will not change an individual's behaviors. According to Devine et al. (2012), racial prejudice is an unconscious habit. In order to break the habit, the individual will have to become aware of the unconscious nature of their racial bias and stereotypes, become concerned that they have this bias, and implement strategies that are effective in retraining their automatic responses to racial stimuli. Devine et al. found that increasing awareness of one's biases will increase their 
concern about how their biases affect their actions and will motivate them to learn strategies to amend their biases and how their biases affect their behaviors.

Knowledge Once an individual becomes aware of their stereotypes, they can begin to increase their knowledge about other cultures and ways to avoid stereotyping. Some effective strategies to replace bias responses with non-bias responses are replacement of stereotypes (recognizing biased responses, considering how the response can be avoided in the future, and replacing them with unbiased responses), counterstereotype imaging (imagining in detail positive aspects of the group that contradicts their negative stereotypes), and individuating members of ethnic groups (looking at them as individuals rather than a group) (Devine et al. 2012). Social workers, teachers, police officers, health professionals, business people, etc. can have this habit-breaking training within the context of their fields, which could reduce unjust treatment and institutional racism in schools, the justice system, health care, and businesses.

As awareness increases, it is also important for people to learn about other cultures. Education is key to dismantling the stereotypes that continue to deny African-American men equal access to education, employment, and other resources in their communities. Educating others can be as simple as presenting them with the research that demonstrates how, why, and when stereotypes are most likely to influence decisions (Grewal 2010). Research shows that educating people about stereotypes helps foster diversity (Grewal 2010). In order to ensure social equity, cultural competency training must be implemented at all levels of society and integrated into social policies.

Another critical piece to dismantling stereotypes is exposure. Having interaction with individuals of different ethnic groups has been effective in increasing knowledge of other cultures and reducing stereotypes (Devine et al. 2012). According to the intergroup theory (Pettigrew 1998), increased contact with diverse individuals and having personal relationships with people from different ethnic groups can lower the level of prejudice toward minorities. This theory explains why people who have friends or personal relationships with diverse people show less discrimination and bias toward members of those groups (Wahler 2012). Lowery (2002) contends that the more opportunities teachers have to interact with different student populations, the more open they will be to accepting diverse student populations. Research has also shown that trainings and activities that involve interactions between diverse groups tend to be more successful in promoting long-term attitudinal changes, compared to those activities simply providing information about minority groups (Oskamp 2000 as cited by Wahler 2012). Petrovish and Lowe (2005) found that people learned the most about groups different from themselves by exposure and relationship building with minority groups and through hearing their personal stories. Eack and Newhill (2008, as cited by Wahler 2012) also found that contact with individuals in a minority group (such as people who are mentally ill) was the most important factor in their comfort level and knowledge about persons with mental illness.

Skills With the insight acquired from cultural competency training and the increased knowledge of other cultures, social workers, educators, law enforcement, and policy makers will gain a skill set that will enable them to provide services that promote social equity for marginalized populations, such as African-American males. Cultural competency training not only allows people to appreciate and embrace the differences, but also enables them to recognize the similarities between cultures. Recognizing and acknowledging similarities may assist professionals (like police officers) in developing rapport with community members different from themselves and may help them react appropriately in culturally diverse situations (Hickey 2016). Understanding different cultures will assist professionals (social workers, police officers, educators, etc.) in diffusing negative situations because they will be able to understand how people from different cultures react in various situations based on their cultural values and beliefs (Hickey 2016). As cultural competent skills are acquired, professionals will treat diverse populations with respect and non-judgmental attitudes congruent with the mandates of the UDHR. It is important to note that cultural competency training will not rid an individual of all their biases. Becoming culturally competent should be viewed as a developmental process and a goal that an individual/agency is continually working toward (Cross 1988). Regardless of how culturally competent an individual/agency becomes, there will always be room for growth (Cross 1988).

\section{Social Work Curriculum}

To correct misconceptions about African-Americans and other cultural groups, students need to learn to distinguish between a valid generalization and a stereotype (Moore 2006). According to Moore (2006), this skill is needed to be able to advocate on behalf of others. Therefore, students must learn about the origins, purposes, and consequences of stereotypes and the ways to combat them in order to provide optimal services to their clients. Research has shown that incorporating diversity or multicultural courses into college curriculums has contributed to a positive change in racial attitudes (Radloff 2010). Therefore, all social work students are required to take a cultural diversity class. However, taking one diversity class is not enough for students to become culturally competent. It is important to engage in ongoing cultural competence training because research supports that individuals who have ongoing training are more effective in delivering culturally 
competent services (Wahler 2012). It is recommended that various assignments targeted at reducing stereotypes and misconceptions be implemented throughout social work curriculums. Such assignments should expose students to direct contact with people from other cultures. For instance, in a human behavior course, an assignment in which a student has to attend a cultural event in which they are the minority may be helpful in increasing awareness on how minorities may feel on a daily basis. In a practice course, an assignment to interview a minority or international student over lunch and then meet with them weekly for 1 month can be used to expose students to other cultures and reduce stereotypes. In research classes, previous studies/experiments such as the Jane Elliott's blue eye brown eyes experiment or Clark and Clark's doll study can be replicated to increase awareness and empathy. Finally, a policy class can take a field trip to a civil rights museum to understand the history of African-Americans and how various events throughout history have impacted institutional racism and race disparities. Policy classes can also be assigned to attend town hall meetings and take trips to the state capitol to lobby against unjust bills being passed.

Advocacy is an important skill for social workers to possess since social justice is a core value of the profession. Cultural competency is a first step to dismantling stereotypes, but policies and laws must be changed to address institutional racism. Therefore, students must be aware of how stereotypes affect laws contributing to institutional racism and assignments designed to strengthen students' advocacy skills should be given. For instance, social work students should be instructed to research policies being introduced in their state that conflict with social work core values. Through research they may find a bill being introduced such as one to drug test all individuals who receive public assistance. This is a social justice issue because it targets a vulnerable population (low income, minorities) and perpetuates the stereotype that people receiving government assistance are substance abusers. In this situation, an assignment can be made to write letters to senators and representatives that are sponsoring the bill. Students can use empirical data in the letters to expose the stereotypes and increase awareness about the unjust policies. Instructors can make arrangements for the class to go to the state capitol and sit in open committee meetings with those sponsoring the bills. There the students can voice concerns about how the particular bill will perpetuate stereotypes and contribute to institutional racism, while using research to support their arguments. These types of assignments are vital to teaching students to advocate against bills and laws that do not have the best interest of vulnerable populations, such as African-American males. If these skills are acquired in school, it is likely that students will continue to advocate and be involved with social justice issues in their communities throughout their careers.

Lobbying against unjust laws and bills is one step to increasing public awareness in attempts to decrease institutional racism. Students should also become familiar with human rights documents such as the UDHR and the CERD and should be trained around anti-racist behaviors and advocacy (Rozas and Garran 2016). Learning to practice from a human rights perspective will enable students to advocate for the right of all individuals to have at the very least a minimal life standard (Rozas and Garran 2016).

\section{CEUs}

Before social workers can train other professionals to be culturally competent, they must first be culturally competent themselves. According to the U.S. Social Work Code of Ethics (2008), social workers should understand culture, provide culturally competent services, and seek to understand social diversity and oppression. Although ethics training is required by nearly every state licensure board, fewer than 10 states require cultural competency training for license renewal. Therefore, social workers should advocate for state licensure boards to mandate a minimum of three continuing educational units of cultural competence training yearly in every state. Like all people, social workers have biases and must address them. If social workers are advocating for mandated cultural competency training in other fields, our profession must show the importance of the training by making it a requirement to obtain/maintain licensure.

\section{Policy Change}

Finally, this article is a call to action for social workers to embrace the role as a change agent in dismantling how society has perpetuated the stereotypes of African-American males. The social work core value of social justice maintains that social workers are to pursue social change on behalf of oppressed individuals, such as African-American males. Hence, it is crucial to increase society's awareness of the stereotypes that play a major role in educational outcomes, hiring processes, and the continued police brutality shown toward African-American males.

One step to achieve this is by lobbying for policies to be passed that mandate and enforce all State and Federal agencies and organizations to participate in cultural competency training as part of their new worker orientation. It is recommended that this training be provided by a certified cultural competency trainer. Although most agencies currently have some sort of diversity training, employees often report that it is not beneficial. Many times the presenter is not competent in the area of training and rushes through the information, and the employee simply signs a sheet indicating they received the training. 
There is a lack of accountability or measure as to how much the employee actually learned. Therefore, this proposed mandated training would require that the participant pass a standardized exam noting the worker's proficiency in the training. No staff would be allowed to move forward in the hiring process until they have demonstrated proficiency in the training with a score of at least $80 \%$. It is also recommended that a refresher course be mandated every year accompanied by a passing score of $80 \%$ to remain employed. To ensure that the mandated cultural competency training is implemented as proposed, State and Federal Agencies not in compliance would be at risk of losing state and federal funding until the agency can produce documentation that all staff have completed the mandated training. Failure to be in compliance will result in a fine per each incidence. If the agency continues to be noncompliant, the state and federal funding will be lost. For policies like this to become a reality, the U.S. National Association of Social Workers must commit to being the voice against social injustice by exposing stereotypes that perpetuate institutional racism and must be committed to lobbying for laws supporting equality and against those that oppress individuals.

In addition to lobbying for policies to mandate and enforce cultural competency training for state and federal employees, social workers can empower clients by assisting them in initiating formal complaints about the institutional racism they have experienced. Organizing forums in the community and facilitating opportunities for African-American males to share their perspectives on how institutional racism has impacted their lives can be effective in increasing awareness and knowledge. Finally, social workers can assist businesses by identifying opportunities to create positive change by constructing expectations and accountability for how the organizations will address institutional racism.

\section{Future Research}

When working with African-American males, it is important to consider the traumatic effects of racism. Social workers and all mental health professionals should acknowledge how stereotypes contribute to racist acts, resulting in trauma. Future research should focus on the psychological effects of racism (increased stress, fear, anger, self- hatred, depression) on African-American males and how their experiences with racism impact their outcomes. Rather than stereotyping African-American males as angry, paranoid, lazy, or substance abusers, social workers should seek to understand the trauma AfricanAmerican males are experiencing and provide culturally sensitive trauma-focused therapy. Perhaps the anger is a result of racist experiences and the paranoia is justified due to continuous stereotypes and unjust treatment. The laziness may be a lack of motivation due to frustration and hopelessness as a result of institutional racism, and the substance abuse may be self-medicating behaviors because mental health professionals are not treating the trauma.

Future studies should also examine historical trauma. As a result of slavery, institutional racism, and years of discrimination, traumas can be transmitted across generations. African-American males do not necessarily have to experience racism directly to experience traumatic effects. For instance, African-American males see daily how they are stereotyped in the media; they often hear their parents talking about not getting interviews, jobs, or promotions because of discrimination; and they see reports of other unarmed African-American males being brutally killed by the police on the news. Although they may not be experiencing these things directly, hearing and seeing these situations can be traumatic, instilling fear, anger, and mistrust. Social workers often experience secondary trauma (compassion fatigue) as a result of being exposed to traumatic material they hear from their clients. Much consideration is given to this and self-care is emphasized in social work departments to reduce the traumatic experiences associated with compassion fatigue. Perhaps, more attention should be given to historical trauma faced by African-American males and effective trauma-focused interventions that will benefit them. Social workers must take action and advocate that racism be included in discussions and definitions of trauma in order to provide appropriate culturally competent services.

\section{Conclusion}

Stereotypes are deeply embedded in U.S. culture and often influence acts of prejudice and systemic racism that have contributed to the inequalities of African-American males. Social workers need to continue to bring awareness to the devastating consequences of stereotypes and their impact on laws and policies that perpetuate race disparities in education and employment outcomes, and arrests and sentencing in the judicial system. Social workers must also advocate for changes at the state and federal level to mandate that cultural competency training is implemented in all state and federal agencies to increase individuals' awareness and knowledge of other cultures that enhance their effectiveness to work with culturally diverse populations. The U.S. government has failed to comply with and enforce CERD, thus allowing human rights violations and racial discrimination to develop, persist, and go unreported and unpunished (Henderson 2013). Social workers need to advocate that the Articles of UDHR and CERD be enforced to adopt immediate and effective measures 
that combat prejudices and promote understanding, tolerance, and friendship among nations and racial or ethnic groups (Henderson 2013).

\section{References}

Aguilar, D. N. (2015). Oppression, domination, prison: the mass incarceration of Latino and African American men. The Vermont Connection, 35(2), 12-20 Retrieved from http://scholarworks.uvm. edu/tvc/vol35/iss $1 / 2$.

Bertand, M. \& Mullainathan, S. (2004). Are Emily adn Greg more employable than Lakisha and Jamal? A field experiment on labor market discrimination. The American Review, 94(4), 991-1013.

Bethell, D. (2012). Igniting a passion for career development success with African American school aged males: what career and school practitioners should know. Journal of Career Planning and Adult Development, $42-56$.

Blackmon, S. M., \& Thomas, A. J. (2014). Linking contextual affordances: examining racial-ethnic socialization and parental career support among African American college students. Journal of Career Development, 41(4), 301-320. https://doi.org/10.1177/ 0894845313495588

BLEAUSA-Blacks in Law Enforcement of America. (2014). Retrieved from http:/www.bleausa.org/modern-police-policies-rooted-in-oldsouth-slave-codes Bridges (2012). Retrieved from https://www. youtube.com/watch? $\mathrm{v}=\mathrm{b} 0 \mathrm{bhSQR} 14 \mathrm{nw}$

Bridges. (2001). Through my eyes. Scholastic Press.

Caldwell, \& Obasi. (2010). Academic performance in African American undergraduates: effects of cultural mistrust, educational value, and achievement motivation. Journal of Career Development, 36(4), 348-369. https://doi.org/10.1177/0894845309349357.

Chaney, C., \& Robertson, R. (2015). Armed and dangerous? An examination of fatal shootings of unarmed Black people by police. Journal of Pan African Studies, 8(4), 45-78.

Chavous, T. M., Rivas-Drake, D., \& Smalls, C. (2008). Gender matters too: the influence of school racial discrimination and racial identity on academic engagement outcomes among African American adolescents. Developmental Psychology, 44(3), 637-654. https://doi. org/10.1037/0012-1649.44.3.637.

CNN. (2010). Study: White and black children biased toward lighter skin. Retrieved from www.cnn.com/2010/US/05/13/doll.study.

Cokley, K., Dreher, G. F., \& Stockdale, M. S. (2004). Toward the inclusiveness and career success of African Americans in the workplace. In M. S. Stockdale \& F. J. Crosby (Eds.), The psychology and management of workplace diversity (pp. 168-190). Malden: Blackwell.

Comfort, M. (2012). It was basically college to us: poverty, prison, and emerging adulthood. Journal of Poverty, 16, 308-322. https://doi. org/10.1080/10875549.2012.695923.

Cornelius, T. H. (2013). "I'm a black man and I'm doing this job very well": how African American professional men negotiate the impact of racism on their career development. Journal of African American Studies, 17, 444-460. https://doi.org/10.1007/s12111-012-9225-2.

Cross, T. L. (1988). Cultural competence continuum. Journal of Child and Youth Care Work, 83-85.

Current Population Survey (CPS) (2008). United States Census Bureau.

Darensbourg, A., Peres, E., \& Blake, J. J. (2010). Overrepresentation of African American males in exclusionary discipline: the role of school-based mental health professionals in dismantling the school to prison pipeline. Journal of African American Males in Education, 1(3), 196-211.

Department of Justice Report. (2016). Retrieved from https://www. justice.gov/crt/file/883296/download.
Devine, P. G., Forscher, P. S., Austin, A. J., \& Cox, W. T. L. (2012). Long term reduction in implicit race bias: a prejudice habit-breaking intervention. Journal of Experimental Social Psychology, 48(6), $1267-1278$.

Diamond, J. B. (2006). Still separate and unequal: Examining race, opportunity, and school achievement in "integrated" suburbs. The Journal of Negro Education, 75(3), 495-506 Retrieved from $\mathrm{http}: / /$ search.proquest.com.proxy1.ncu.edu/docview/222067021? accountid $=28180$.

Dulaney, W. M. (1996). Black police in America. Bloomington, IN: University of Indiana Press.

Fachner, G., \& Carter, S. (2015). An assessment of deadly force in the Philadelphia police department. Collaborative Reform Initiative. Retrieved from https://ric-zai-inc.com/Publications/cops-w0753pub.pdf.

Feagin, J., \& Feagin, C. (1999). Racial and ethnic relations (6th ed.). Upper Saddle River: NJ Prentice Hall.

Fisher, M. J. (2009). A longitudinal examination of the role of stereotype threat and racial climate on college outcomes for minorities at elite institutions. Social Psychology Education, 13(1), 19-40. https://doi. org/10.1007/s11218-009-9105-3.

Ford, D. Y., \& Whiting, G. W. (2007). A mind is a terrible thing to erase: Black students underrepresentation in gifted education. Multiple Voices, 10(1\&2), 28-44.

Frye, B. J., \& Vogt, H. A. (2010). The causes of underrepresentation of African American children in gifted programs and the need to address the problem through more culturally responsive teaching practices in teacher education programs. Black History Bulletin, 73(1), $11-17$.

Giller, E. (1999). What is psychological trauma? Sidran Institute. https:// www.sidran.org/resources/for-survivors-and-loved-ones/what-ispsychological-trauma/.

Givens, J. R., Nasir, N., Ross, K., \& DeRoyston, M. M. (2016). Modeling manhood: reimaging Black male identities in school. Anthropology and Education Quarterly, 47(2), 167-185. https://doi.org/10.1111/ aeq. 12147.

Gregory, A., Skiba, R. J., \& Noguera, P. A. (2010). The achievement gap and the discipline gap: two sides of the same coin? Educational Researcher, 39(1),59-68. https://doi.org/10.3102/ 0013189 X09357621.

Grewal, D. (2010). Reducing the impact of negative stereotypes on the careers of women and minority scientists. Science.

Griffith, et al. (2007). Dismantling institutional racism: theory and action. American Journal of Community Psychology., 39(3-4), 381-392. https://doi.org/10.1007/s10464-007-9117-0.

Hadden, S. (2001). Slave patrols: Law and violence in Virginia and the Carolinas. Cambridge: Harvard University Press.

Harpalnai, V. (2017). Counterstereotypic identity among high-achieving Black students. Urban Education Journal, 14(1), 1-9.

Harvard Law Review. (1991). Invisible man: Black and male under Title VII. Harvard Law Review, 104(3), 749-768.

Henderson, L. (2013). Why is racial injustice still permitted in the United States? An international human rights perspective on the United States' inadequate compliance with the international convention in the elimination of all forms of racial discrimination. Wisconsin International Law Journal, 31(2), 323-351 Retrieved from https:// hosted.law.wisc.edu/wordpress/wilj/files/2014/01/Herndon_final_ v2.pdf.

Henfield, M. S., Moore, I. L., \& Wood, C. (2008). Inside and outside gifted education programming: hidden challenges for African American students. Exceptional Children, 74(4), 433-450 Retrieved from: http://content.ebscohost.com/pdf9/pdf/2008/EXC/ 01May08/32968612.pdf?T $=P \& P=A N \& K=32968612 \& S=R \& D$ $?=\mathrm{eh} \mathrm{h} \& \mathrm{~Eb} \mathrm{~s}$ c o C o n te $\mathrm{t}=\mathrm{d}$ G J y M N H 7 E S e p r ?A4wtvhOLCmr0qep7ZSrqe4S7aWxWXS\&ContentCustomer= dGJyMPGnsEq3q7FIuePfgeyx43zx. 
Herrnstein, R. J., \& Murray, C. (1994). Bell curve: intelligence and class structure in America life. New York: Free Press Paperbook.

Hickey, R. (2016). Should cultural competency be a part of police testing? Law Enforcement Executive Forum, 16(2), 85-97.

James, C. E. (2012). Students "at risk": stereotypes and the schooling of black boys. Urban Education, 47(2), 464-494. https://doi.org/10. $1177 / 0042085911429084$.

Jennings, R. (2011). From slavery to contemporary genocide: a literary and linguistic analysis of why American Blacks deserve reparations. Race, Gender, \& Class, 18(1/2), 73-94.

Johnson-Bailey, J., Ray, N., \& Lasker-Scott, T. (2014). Race, the Black male, and heterogeneous racism in education. New Directions foe adult and Continuing Education, 144(5-14). https://doi.org/10. 1002/ace.20109.

Judd, C. M., \& Park, B. (1993). Definition and assessment of accuracy in social stereotypes. Psychological Review, 100(1), 109-128.

Larnell, G. V., Boston, D., \& Bragelman, J. (2014). The stuff of stereotypes: toward unpacking identity threats amid African American students' learning experiences. Journal of Education, 194(1), 4957.

Lowery, R. M. (2002). Grappling with issues of gender equity: preservice teachers' reflections on children's books. Journal of children's literature, 28(2), 25-32.

Mathew, J. S., Kizzie, K. T., Rowley, S. J., \& Cortina, K. (2010). African Americans and boys: understanding the literacy gap, tracing academic trajectories, and evaluating the role of learning-elated skills. Journal of Educational Psychology, 102(3), 757-771 Retrieved from https://www.researchgate.net/publication/232538334 African_Amerians_and_Boys_Understanding_the_Literacy_Gap_Tracing_Academic_Trajectories_and_Evaluating_the_Role_of_ Learning-Related Skills.

Mathew, E. M. (2011). Effort optimism in the classroom. Sociology of Education, 84(3),225-245.

Mattison, E., \& Aber, M. S. (2007). Closing the achievement gap: the association of racial climate with achievement and behavioral outcomes. American Journal of Community Psychology, 40(1-2), 1-12. https://doi.org/10.1007/s10464-007-9128x.

Mauer, M. (2011). Addressing racial disparities in incarceration. The Prison Journal, 91(3), 87S-101S. https://doi.org/10.1177/ 0032885511415227.

Moore, J. (2006). Shattering stereotypes: a lesson plan for improving student attitudes and behavior toward minority groups. The Social Studies, 97(1), 35-39 Retrieved from http://eds.a.ebscohost.com/ eds/pdfviewer/pdfviewer?vid=2\&sid=f1 bdaac8-a2db-49ff-ac5144f44088ea5ba\%40sessionmgr4006.

National Association of Social Worker. (2008). Social work code of ethics. Retrieved from https://www.socialworkers.org/LinkClick. aspx ?fileticket $=\mathrm{KZmmbz} 15 \mathrm{evc} \% 3 \mathrm{D} \&$ portalid $=0$.

National Association of Social Workers Code of ethics. (2017). Retrieved from https://urldefense.proofpoint.com/v2/url?u=https-3A www. socialworkers.org_About_Ethics_Code-2Dof-2DEthics_Code2 Dof- 2 DEth ics- 2 DEng $\bar{l}$ is h \& d = D w I G a Q \& c = vh6FgFnduejNhPPD0f1_yRaSfZy8CWbWnIf4XJhSqx 8\&r= ao7Vv0uBvRwgd0ykVbHjMjeV7vz8HzQ1 TmA0JYOvo ? $\mathrm{N} \mathrm{u} \mathrm{K} \mathrm{u} \mathrm{A} \mathrm{v} \mathrm{W} \mathrm{N} \mathrm{p} \mathrm{c} 1$ t s y S H n $\mathrm{x}$ Z L M \& m = CNHdbCVvTaZqPI2mol6M100GMrBSzsR80RKxYa8x8GY\&s= KnNrBX-FSKXObmrXsrQMmO9WjzMDLd0Tjjs4K1_ oOdk\&e $=$.

National Center for Educational Statistics. (2010). Retrieved from www. nhttps://www.socialworkers.org/LinkClick.aspx?fileticket=ms ArtLqzeI\%3d\&portalid=0ces.ed.gov $/$.

National Center for Educational Statistics. (2016). Retrieved from www. nces.ed.gov/.

Neal, L. V. I., McCray, A. D., Webb-Johnson, G., \& Bridgest, S. T. (2003). The effects of African American movement styles on teachers' perceptions and reaction. The Journal of Special
Education, 37(1). Retrieved from http://web.pdx.edu/ jhumn/ Neal\%20et.\%20al.pdf), 49-57.

Nosek, B. A., Hawkins, C. B., \& Frazier, R. S. (2011). Implicit social cognition: from measures to mechanisms. Trends in Cognitive Science, 15(4), 152-159.

Ogbu, J. U. (2004). Collective identity and the burden of "acting White" in black history, community and education. The Urban Review, $36(1), 1-35$.

Oliver, M. (2003). African American men as "criminal and dangerous": implications of media portrayals of crime on the "criminalization" of African American men. Journal of African American Studies, 7(2). Retrieved from: http://www.jstor.org/stable/41819017), 3-18.

Pager, D. (2003). The mark of a criminal record. American Journal of Sociology, 108(5), 937-975 Retrived from http://www.jstor.org/ stable/10.1086/374403?seq=25\#page_scan_tab_contents.

Perry, \& Bright. (2012). African American fathers and incarceration: paternal Involvement and child outcomes. Social Work in Public Health, 27, 187-203. https://doi.org/10.1080/19371918.2011. 629856.

Petrovish, A., \& Lowe, M. (2005). Developing cultural competence: student and alumni perspectives. Journal of Teaching in Social Work, 25(3/4), 157-176.

Pettigrew, T. F. (1998). Intergroup contact theory. Annual Review of Psychology, 49(1), 65-85.

Plous, S., \& Williams, T. (1995). Racial stereotypes from the days of American slavery: a continuing legacy. Journal of Applied Social Psychology, 25(9), 795-817.

Radloff, T. D. L. (2010). College students' perception of equal opportunity for African Americans and race-based policy. Do diversity course requirements make a difference? College Studies, 44(2), $558-564$.

Reynolds, Sneva, \& Beehler. (2010). The influence of racism related stress on the academic motivation of Black and Latino students. Journal of College Student Development, 51(2), 135-149.

Robinson, L., Smith, M., \& Segal, J. (2018). Emotional and psychological trauma: Healing and moving on. HELPGUIDE.Org. Retrieved from https://www.helpguide.org/articles/ptsd-trauma/coping-withemotional-and-psychological-trauma.htm.

Rosette, A. S., Leonardelli, G. J., \& Phillips, K. W. (2008). The White standard: Racial bias in leader categorization. Journal of Applied Psychology, 93(4), 758-777. https://doi.org/10.1037/0021-9010. 93.4.758.

Rozas, L. W., \& Garran, A. M. (2016). Towards a human rights culture in social work education. British Journal of Social Work, 46(4), 890905. https://doi.org/10.1093/bjsw/bcv03.

Rudd, T. (2014). Racial disproportionality in school discipline: Implicit bias is heavily implicated. Kirwan Institute Issue Brief. Retrieved from http://kirwaninstitute.osu.edu/wp-content/uploads/2014/02/ racial-disproportionality-schools-02.pdf.

Sibrava, N.J., Perez Benitez, A.C.I., Weisberg, R.B., Bjornsson, A.S., Moitra, E., \& Keller, M.B. (2019). Posttraumatic stress disorder in African American and Latinx adults: Clinical course and the role of racial and ethnic discrimination. American Psychologist, 74(1), 101-116. https://doi.org/10.1037/amp0000339.

Skibam, R. J., Arredondo, M. I., \& Williams, N. T. (2014). More than a metaphor: The contribution of exclusionary discipline to a schoolto-prison pipeline. Equity \& Excellence in Education, 47(4), 546564. https://doi.org/10.1080/10665684.2014.958965.

Smith, B., \& Holmes, M. (2003). Community accountability, minority threat, and police brutality: an examination of civil rights criminal complaints. Criminology, 41(4), 1035-1064.

Sparks, S. D. (2016). One key to reducing school suspension: a little respect. Education Week, 35, 8-12 Retrieved form hhtp://www. wditdigest.com. 
Steele, \& Anderson. (1995). Stereotype threat and the intellectual test performance of African Americans. Journal of Personality and Social Psychology, 69(5), 797-811.

Steward, A. D., \& Cunningham, G. B. (2015). Racial identity and its impact on job applicants. Journal of Sports Management, 29, 245256. https://doi.org/10.1123/jsm.2014-0017.

Tenenbaum, H. T., \& Ruck, M. D. (2007). Are teachers' expectations different for racial minority than for European American students? A meta-analysis. Journal of Educational Psychology, 99(2), 253273.

The Nation's Report Card (2013). Retrieved from https://www. nationsreportcard.gov/reading_math_2013/\#/.

Turner, K., Giacopassi, \& Vandiver. (2006). Ignoring the past: coverage of slavery and slave patrols in criminal justice texts. Journal of Criminal Justice.

U.S. Bureau of the Census. (2010). Retrieved from https://www.census. gov/topics/income-poverty/poverty/data.html.
United Nations. (1948). The Universal Declaration of Human Rights. Retrieved from: http://www.un.org/en/universal-declarationhuman-rights/.

US Department of Education, National Center of Education. (2010). Retrieved from https://nces.ed.gov/.

US Department of Education Office for Civil Rights. (2014). Civil rights data collection, Data Snapshot: School Discipline. Retrieved from https://ocrdata.ed.gov/downloads/crdc-school-discipline-snapshot.pdf.

US Department of labor, Bureau of labor statistics. (2007). Retrieved from https://www.bls.gov/cps.

US Department of labor, Bureau of labor statistics. (2011). Retrieved from https://www.bls.gov/.

Wahler, E. A. (2012). Identifying and challenging social work student biases. Social Work Education, 31(8), 1058-1070.

Publisher's Note Springer Nature remains neutral with regard to jurisdictional claims in published maps and institutional affiliations. 